\title{
To keep up, go beyond
}

\section{Developing a personal professional development plan using e-resources outside the bounds of library literature}

by Steven J. Bell

$\mathrm{H}$ ow are you keeping up?" is a question that academic librarians are asking each other more frequently. It reflects our considerable efforts to cope with the deluge of information needed to keep pace with the rapid and turbulent change affecting the library profession.

Through its literature, conferences, and member interaction, librarianship offers multiple mediums for keeping personal professional skills current. But "keeping up," and, in fact, staying ahead on the innovation and creativity curve, requires academic librarians to go beyond the boundaries of their own professional development resources. This article identifies strategies for developing a personal current awareness program that draws from disciplines beyond our own.

The complexity of academic librarianship and the number of skills and technologies required for professional competency has radically altered the concept of "keeping up with change." It goes beyond being familiar with the latest library technologies or knowing the features in the latest version of an electronic database.

Change in fields once thought far afield or peripheral to our own, such as higher education, communications, computers, and instructional technologies, are today's innovation incubators. Keeping up with changes in those fields in addition to our own may seem an insurmountable task. The challenges are to find the sources that channel news of change to you in a way that requires minimal individual effort, and then to control your intake and digestion of information to avoid being overwhelmed.

\section{Categories of resources for keeping up}

New technologies have changed the rules for keeping up, but also simplify the task. The old model depended largely on paper formats, while the new one relies on electronic publishing and distribution. Print is far from obsolete, but a thorough current awareness strategy must use electronic resources, especially for scanning diverse disciplines.

"Push" also characterizes these new literature formats. Either by subscription or other alerting technology, the latest information can be delivered to an e-mail inbox as easily as printed subscriptions appear in a physical mailbox. These new technologies fall into one of two categories:

- e-newsletters (sometimes called e-zines) and

- Web-based resources (magazines, journals and newspapers, Web sites, and Web pages).

As a mechanism for delivering concise and targeted information, newsletters are ideal. They cover a wide range of technologies and skill development. The migration from print to e-format increases their utility. The defin-

\section{About the author}


ing characteristics of the e-newsletter are email delivery and hypertext. With their embedded links, the reader is often but a click away from discovery. If you don't mind advertisements, many are freely distributed

E-newsletters themselves may fall into different categories. The most common type is an amalgam of text and links. Story items are usually brief and link to a Web page offering additional information. E-newsletters offering advice and commentary may often contain longer stories without links. There are no set boundaries, and the landscape abounds with hybrids.

Web-based resources can also be further divided by type. One subcategory includes magazines, journals, and newspapers. The other consists primarily of Web sites and pages that, when updated, report new information. Publications in the former subcategory typically provide full-text articles and industry news. The burden of keeping track of the release of new issues on these sites falls to the individual; though some publications are beginning to offer e-mail alerts of new issues, few offer such mechanisms. Tracking changes can be difficult.

Falling into the latter subcategory is the Web site or page that is periodically updated, but which is not intended to transmit information. These pages may have new, significant information two days in a row, and go static for weeks. You'd like to know whenever new information is added, but it is inefficient to check these resources on a routine basis. Taking advantage of Web-based publications and pages requires a device that provides an alert whenever a page has new information added, and does so via e-mail messages. Using a combination of resources in all three categories is a formula for a powerful and effective strategy for keeping up.

\section{Delivered to your inbox}

Relatively easy to publish and distribute, enewsletters are becoming widely available in several areas of interest to academic librarians. The newsletters of greatest interest fall into four groups:

- higher education,

- instruction, teaching, and learning,

- Web technologies and design, and

- cool or new Web sites.
Here are some examples (URLs where more information is available are provided):

- Chronicle of Higher Education. While a subscription is necessary, some of the stories are provided free at the Web site of the Cbronicle. The daily e-mail is divided into subject areas to facilitate honing in on sections of interest, such as information technology or distance learning. Go to http:// chronicle.com for additional information. Higher education associations, such as the American Association of Higher Education or the American Council on Education, are other potential sources of news about developments in academia.

- Online Learning News. Free with advertisements, this newsletter combines text and links and is a rich source of ideas for bil)liographic instruction and e-training. It focuses on techniques and products for electronic education, onsite and from a distance. Many of the items come from subscribers. It is published every other week. Access: http:// www.emailpub.com/lakewood.

- WebReference Update. Reports on all types of Web site technologies, including JAVA, ASP, XML, multimedia technologies, and nearly any other cutting-edge technology that will help readers improve their Web sites. A recent issue included stories on using dingbats and clip art as Web graphics, and writing "friendly" HTML code. It is free, includes advertisements, is weekly, and has text and links. Access: http://www.webreference.com/ new.

- WebPromote Weekly. Though clearly focused on the commercial Web site community, this free newsletter focuses on marketing and usability. What library can ignore information on how to improve a Wel site? It is a good source for new ideas, covering topics such as statistics, user surveys, and multimedia Web technologies. It does contain

\section{More "keeping up" sites}

There are more "keeping up" resources from within and beyond librarianship than can be contained in this article. For more information visit the "Keeping Up" Web page at http://staff.philau.edu/bells/ keepup.htm. 


\section{... consider the value of}

\section{discovering one new piece of}

information, software product, or

Web site that could save time,

increase productivity, provide

better service, or simply raise the

library's profile.

advertisements, and features both text and links. Access: http://www.webpromote.com.

- Internet Tour Bus. Essentially a listing of cool and new Web sites that may be new additions to your Internet resource links or a potential source of new information for professional development, the Tour Bus is free and contains minimal advertising. It tends to give reliable information on viruses, hoaxes, and developments at technology companies. Access: http://www.tourbus.com.

\section{Minding it on the Web}

Web-based publications rarely offer a mechanism for upclate notification. That is why NetMind's Mind-It service is an essential tool for a keeping up strategy. Mind-It is simple and free. Anytime a URL in a subscriber's profile changes, the subscriber is alerted by email. The message contains a link to the page, making it easy to then connect. One's profile can be modified at any time to add or delete URLs. To find out more, go to http:// www. netmind.com/ $\mathrm{html} /$ individual.html. A potential drawback is that some pages constantly are affected by minor change. Mind-It will not distinguish between important and inconsequential change. That may result in constant alerts of which few are of real value. There is a customization that can minimize this particular problem.

Web publications, sites, and pages tend to fall into the same categories as e-newsletters. Here are some additional examples of Web sites and pages that can be monitored with Mind-It

- Alertbox: Jakob Nielsen's Column on Web Usability. Nielsen is a recognized expert on Web usability. Any librarian who manages or contributes to a Web site will benefit from Nielsen's insights into what makes a page work best. This is a free resource that carries no advertisements. Access: http://www.useit.com/ alertbox.

- New York Times Technology Page. This Web page covers developments in computer and high technology fields. It is updated daily, but, to keep up, just follow the weekly digest, called the "seven day index." It's a quick way to stay abreast of cuttingedge technology, and follow the Web and Internet news. Access: http://www.nytimes. $\mathrm{com} / \mathrm{yr} / \mathrm{mo} / \mathrm{day} / \mathrm{tech} /$ index 7 day.html.

- Networking: The Node. Just one example of the several pages devoted to the advancement of technology for teaching and learning. It disseminates news about activities and developments in distance education and learning technologies. Recent issues included stories on new interactive learning programs and innovative electronic classrooms. It is free and has no advertising. Access: http://thenode. org/networking.

- Educational Technology \& Society. A free, full-text Web-based journal. Recent issues included topics such as lifelong learning and the ubiquitous use of technology in education. Issues also include Web site and book reviews and a column that explains new instructional technology devices. Access: hıtp:// ifets.ieee.org/periodical.

\section{Avoid getting overwhelmed}

One hazard in any keeping up strategy occurs when reading and reviewing alerts amount to an hour or more a day. Few of us can afford to allot that much workday time to this task. To prevent it from becoming a time-consuming burden, here are some strategies for minimizing the time devoted to keeping up.

- Be a browser. Many of the publications will be peripheral and you will want to follow-up on only ten or twenty percent of the total. Get skilled at browsing. Do not attempt to read them in detail. Concentrate on spotting the one or two items you need to know.

- Use your e-mail client to get organized. Many e-mail software programs allow users to identify messages coming from specific addresses for routing to folders. Create a "keeping up" folder and set aside 15 minutes each day to scan its contents rather than stopping other activities throughout the day to read materials just arriving in your inbox.

- Print or capture and review later. Many "keeping up" resources primarily identify Web 
sites, and considerable time is spent visiting sites of interest to determine if they can be of further use. Avoid making those determinations online. It can be more efficient to make a quick site visit to print that page or use your browser to capture the page for offline viewing. Use your offline time to determine those sites worth a return visit.

- Share the load and tackle it as a team. Develop a list of all of the e-newsletters and sites you follow. Ask co-workers to join in a "keeping up" club. This distributes the load and recluces the likelihood of any individual getting overwhelmed. Participants can easily share important items by forwarding or cutting and pasting news into e-mail messages. My staff and I quickly and simply alert each other to significant news items, and we provide proactive service to faculty and other administrators by sharing important news items we know they will want to see

\section{Conclusion}

To discover new ideas and resources that could lead to innovation, librarians need to explore other fields. Our own literature communicates the latest trends in the theory and practice in librarianship, and it makes possible the ongoing dialogue needed to advance the profession. But we need to go beyond this. We must be conversant with our colleagues who are instructional and computer technologists, and be able to understand the realms in which they operate. Others in our organizations respect our expertise and look to us for leadership and guidance in navigating through these turbulent times of fast-paced technological change. So what we know about the landscape of the information age must be more than what we learned in our own profession.

Efforts to keep up will expend your most precious commodity, time. But consider the value of discovering one new piece of information, software product, or Web site that could save time, increase productivity, provide better service, or simply raise the library's profile.

Time is the resource we must trade off to keep up, and there is no certain payoff. In that sense, keeping up is an acrivity not unlike an investment. It is risky because there is something to lose and there is no guaranteed return. But like an investment, if done cautiously, wisely, and with a clear strategy, there is no limit to what might be gained.

\section{*ChoiceReviews.online It's more than just a database of reviews!}

$\star$ Access to nearly 70,000 reviews via the Internet

$\star$ E-mail notification of new reviews, based on individual subject interests

$\star$ Customized list creation, storage, and management

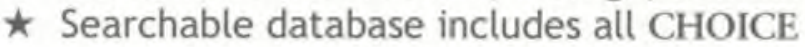
reviews since September 1988

$\star$ Password access allows high degree of customized use

$\star$ SUBSCRIBE NOW for $\$ 395$ !

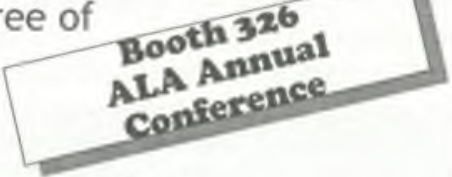

* Sign up for a free trial today!

www.ChoiceReviews.org

Phone: (860)347-6933 x33 Fax: (860) 704-0465 *

* E-mail: subscriptions@ala-choice.org

100 Riverview Center, Middletown, CT 06457 


\section{An exciting, new chapter in e-journal solutions}

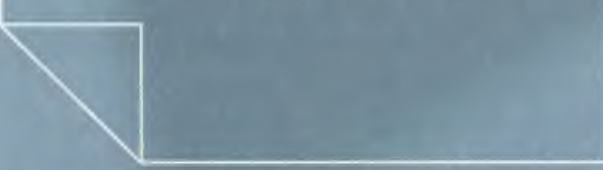

For over 100 years, Faxon. Rowecom Acaderric and Medical Servicess have been the authority in helping libraries acguire and manage print subscripbions. As we tum the page oe a bold new century where electrocic resourcts and Web innovitiens are chalengieg fbraries to reiewent their approach bo information bcoess, Fazon introduces an excifing, new chapter in erjoumai solutions.

Out comprebensive, state-of the-ert products and services will empower you to manape all your electronk colloctions efficiently and effectively, from identification to access, while still providing you with the some level of quelity senvice and support that has been the halmark of Faxon.

From the best selling authority on the subject.

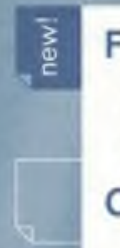

\section{Faxon Licensing Service}

A ground-breaking license negotiation and registration service that gives Faxon the legal authority to act on your library's behalf with publishers.

\section{Core Services}

Our team of experienced client service representatives and electronic resource specialists work as your partner in the identification, selection, acquisition, registration and ongoing maintenance of your electronic journal collection.

\section{License Depot ${ }^{-}$ \\ www.faxon,com/ld}

This unique service contains a Web database of extersive e-journal information, including pricing, licensing and registration terms and conditions. Additionally, it provides vital links to license agreements and registration forms at publishers' websites.

\section{Information Quest (IQ)}

www.informationquest.com

Our leading-edge e-journal delivery solution features desktop access and delivery of full image content from over 3,000 online journals, as well as citations and abstracts from over $\mathbf{2 0 , 0 0 0}$ journals. Combine a powerful search engine with automatic set up and authentication of your electronic subscriptions and you have the answer to simplified e-journal access and management. 